\title{
Variation in Care in the Management of Children With Crohn's Disease: Data From a Multicenter Inception Cohort Study
}

\author{
Chenthan Krishnakumar, MD, ${ }^{*}$ Cortney R. Ballengee, MD, ${ }^{*}$ Chunyan Liu, MS, ${ }^{+}$Mi-Ok Kim, PhD, ${ }^{\neq}$ \\ Susan S. Baker, MD, ${ }^{\S}$ Robert N. Baldassano, MD," Stanley A. Cohen, MD," Wallace V. Crandall, MD,* \\ Lee A. Denson, MD, ${ }^{+\dagger}$ Marla C. Dubinsky, MD, ${ }^{\neq \neq}$Jonathan Evans, MD, ${ }^{\$ \S}$ Ranjana Gokhale, MD, ${ }^{\text {,q }}$ \\ Anne Griffiths, MD, "l' Stephen L. Guthery, MD, ${ }^{* * *}$ Maria Oliva-Hemker, MD, ${ }_{1}^{++t}$ Melvin B. Heyman, MD, ${ }^{\neq \neq \neq}$

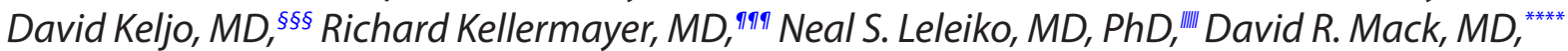

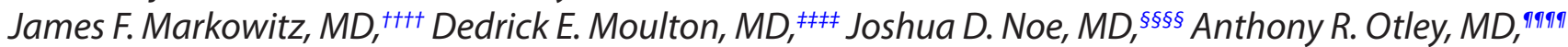 \\ Ashish S. Patel, MD, Marian Pfefferkorn, MD, ${ }^{* * * * *}$ Shervin Rabizadeh, MD, ${ }^{+t+t+}$ Joel R. Rosh, MD, ${ }^{\neq \neq \neq \neq \neq \neq}$

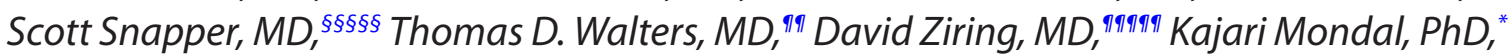 \\ Michael D. Kappelman, MD, ImIII Jeffrey S. Hyams, MD, ${ }^{* * * * * * * * * *}$ and Subra Kugathasan, MD*
}

Background: Variation in care is common in medical practice. Reducing variation in care is shown to improve quality and increase favorable outcomes in chronic diseases. We sought to identify factors associated with variation in care in children with newly diagnosed Crohn's disease (CD).

Methods: Prospectively collected data from a 28-site multicenter inception CD cohort were analyzed for variations in diagnostic modalities, treatment, and follow-up monitoring practices, along with complicated disease outcomes over 3 years in 1046 children. Generalized linear mixed effects models were used to investigate the intercenter variations in each outcome variable.

Results: The mean age at diagnosis was 12 years, and 25.9\% were nonwhite. The number of participants ranged from 5 to 112 per site. No variation existed in the initial diagnostic approach. When medication exposure was analyzed, steroid exposure varied from $28.6 \%$ to $96.9 \%(P<0.01)$ within 90 days, but variation was not significant over a 3-year period $(P=0.13)$. Early anti-tumor necrosis factor (anti-TNF) exposure (within 90 days) varied from $2.1 \%$ to $65.7 \%(P<0.01)$, but variation was not significant over a 3-year period $(P>0.99)$. Use of immunomodulators (IMs) varied among centers both within 90 days $(P<0.01)$ and during 3 years of follow-up $(P<0.01)$. A significant variation was seen at the geographic level with follow-up small bowel imaging and colonoscopy surveillance after initial therapy. 2018 .

Received for publications September 7, 2018; Editorial Decision October 25,

From the *Division of Pediatric Gastroenterology, Department of Pediatrics, Emory University School of Medicine \& Children's Healthcare of Atlanta, Atlanta, Georgia; 'Division of Biostatistics and Epidemiology, Cincinnati Children's Hospital Medical Center, Cincinnati, Ohio; ${ }^{\star D}$ epartment of Epidemiology and Biostatistics, University of California, San Francisco, California; $\$$ Department of Digestive Diseases and Nutrition Center, University at Buffalo, Buffalo, New York; "Division of Gastroenterology and Nutrition, Children's Hospital of Philadelphia, Philadelphia, Pennsylvania; 'Department of Pediatrics, Children's Center for Digestive Health Care, LLC, Atlanta, Georgia; ${ }^{* *}$ Department of Pediatric Gastroenterology, Nationwide Children's Hospital, The Ohio State University College of Medicine, Columbus, Ohio;

${ }_{\dagger}$ Division of Pediatric Gastroenterology, Hepatology, and Nutrition, Cincinnati Children's Hospital Medical Center, Cincinnati, Ohio; Department of Pediatrics, Mount Sinai Hospital, New York, New York; ${ }^{\$}$ Department of Pediatrics, Nemours Children's Specialty Care, Jacksonville, Florida; "Department of Pediatrics, The University of Chicago, Chicago, Illinois; "Division of Pediatric Gastroenterology, Hepatology and Nutrition, Department of Pediatrics, The Hospital for Sick Children, University of Toronto, Toronto, Ontario, Canada; ${ }^{* * *}$ Department of Pediatrics, University of Utah, Salt Lake City, Utah; ${ }^{\dagger \dagger}$ Department of Pediatrics, John Hopkins University School of Medicine, Baltimore, Maryland; 森Department of Pediatrics, University of California at San Francisco, San Francisco, California; ${ }^{\$ s \$}$ Department of Gastroenterology, Children's Hospital of Pittsburgh of UPMC, Pittsburgh, Philadelphia; "TSSection of Pediatric Gastroenterology, Baylor College of Medicine, Texas Children's Hospital, Houston, Texas; 'I"Department of Pediatrics, Hasbro Children's Hospital, Brown Medical School, Providence, Rhode Island;

${ }^{* * * *}$ Department of Pediatrics, Children's Hospital of Eastern Ontario IBD Centre and University of Ottawa, Ottawa, Ontario, Canada; ${ }^{\dagger+\dagger}$ Department of Pediatrics, Cohen Children's Medical Center of New York, Northwell Health, New Hyde Park, New York; Medicine, Nashville, Tennessee; ${ }^{8 s s}$ Department of Pediatric Gastroenterology, Hepatology, and Nutrition, Medical College of Wisconsin, Milwaukee, Wisconsin; "rTा Department of Pediatrics, Dalhousie University, Halifax, Nova Scotia, Canada; "wD Department of Pediatrics, University of Texas Southwestern Medical Center, Dallas, Texas; ${ }^{* * * * *}$ Division of Pediatric Gastroenterology, Hepatology and Nutrition, Indiana University School of Medicine, Indianapolis, Indiana; ${ }^{+\cdots+\dagger}$ Department of

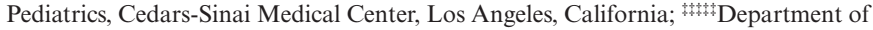
Pediatrics, Goryeb Children's Hospital, Morristown, New Jersey; ${ }^{\$ s s s}$ Department of Gastroenterology and Nutrition, Boston Children's Hospital, Boston, Massachusetts; "กाTा Department of Pediatrics, UCLA David Geffen School of Medicine, Los Angeles,

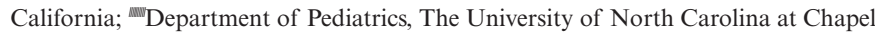
Hill, Chapel Hill, North Carolina; ${ }^{* * * * *}$ Division of Digestive Diseases, Hepatology, and Nutrition, Connecticut Children's Medical Center, Hartford, Connecticut

Conflicts of interest: No conflicts of interest to report for any of the authors. Supported by: Crohn's and Colitis Foundation.

Address correspondence to: Subra Kugathasan, MD, Division of Pediatric Gastroenterology, Emory University School of Medicine \& Children's Healthcare of Atlanta, 1760 Haygood Drive, W-427, Atlanta, GA 30322 (skugath@emory.edu). 
Conclusions: Intercenter variation in care was seen with the initial use of steroids and anti-TNF, but there was no difference in total 3-year exposure to these drugs. Variation in the initiation and long-term use of IMs was significant among sites, but further research with objective measures is needed to explain this variation of care. Small bowel imaging or repeat colonoscopy in CD patients was not uniformly performed across sites. As our data show the widespread existence of variation in care and disease monitoring at geographic levels among pediatric CD patients, future implementation of various practice strategies may help reduce the variation in care.

Key Words: pediatric, quality improvement, outcome, anti-TNF

\section{INTRODUCTION}

Crohn's disease $(\mathrm{CD})$ is one of the chronic disorders frequently seen in pediatric gastroenterology practices in North America. As $\mathrm{CD}$ is not a reportable disease, it is difficult to estimate the prevalence of $\mathrm{CD}$ among children accurately. However, the extrapolation of insurance claims data and other population-based regional data estimate that about 80,000 children currently carry a diagnosis of $\mathrm{CD}$ in the United States. ${ }^{1,2}$ Although many treatment modalities are employed by practicing gastroenterologists, a limited number of medications (only 2) are Food and Drug Administration (FDA) approved for CD in children. ${ }^{3-6}$ There is a paucity of standardized practice guidelines, and variation in care of children with $\mathrm{CD}$ is common..$^{7-11}$ Variation in care with respect to diagnostic approaches, treatment choices (including the use of biologics), and disease monitoring is further influenced by physician style, costs, insurance status, and patients' preferences/ expectations. ${ }^{7,8,12-15}$ All these factors could collectively contribute to variation in care and the management of pediatric $\mathrm{CD}$.

Reducing variation in care and adhering to evidence-based practice guidelines has improved the outcomes of children with chronic diseases. ${ }^{12}$ For instance, outcomes for chronic, often fatal, medical conditions, including cystic fibrosis and childhood cancers have drastically improved by strictly adhering to protocolized clinical trial-based guidelines. ${ }^{13}$ A systematic approach to examine the variation of care among $\mathrm{CD}$ was undertaken by Kappelman and colleagues a decade ago. ${ }^{8}$ Using a prospective pediatric inflammatory bowel disease (IBD) registry, this study examined the practice variation among 311 children with CD enrolled between 2002 and 2005 at 10 centers in North America. Widespread intercenter variation in the management of newly diagnosed children with $\mathrm{CD}$ was seen at multiple levels. A quality improvement project, Improve Care Now (ICN), was launched at a later time point, and 1 of the objectives of the initiative was to reduce the variation of care among children with $\mathrm{CD} .{ }^{16-18}$

We have an unprecedented opportunity to revisit the variation of care and management differences among newly diagnosed CD in North America after the initial report from Kappelman et al. ${ }^{8}$ We sought to use the Risk Stratification and Identification of Immunogenic and Microbial Markers of Rapid Disease Progression in Children with Crohn's disease (RISK) cohort for this purpose. This inception cohort study was launched in 2008 and recruited 1046 newly diagnosed treatment-naïve CD patients from 28 centers. This cohort involved prospective, standardized 6-month data collection, and all participants were followed for a minimum of 3 years where the treatment decision was left to the clinicians without protocolized standard regimes. The objectives of the current study were to (1) assess intercenter variation in diagnostic testing, (2) examine intercenter variation in treatment approaches, and (3) evaluate whether geography of the site is associated with variation.

\section{METHODS}

\section{Study Population and Centers}

The Crohn's and Colitis Foundation supported the RISK inception cohort study, which enrolled 1046 pediatric $(<18$ years old) patients diagnosed with $\mathrm{CD}$ (nonstricturing, nonpenetrating) from 28 North American centers (including 3 from Canada) from November 2008 to June 2012 (ClinicalTrials.gov Identifier: NCT00790543). Geographic regions were divided into the Midwest, Northeast, South, and West according to US Census Bureau geographic atlas regions published in $2010 .{ }^{19} \mathrm{We}$ have included 3 Canadian sites into the Northeast category as all 3 Canadian sites were situated along Eastern Canada.

\section{Ethical Considerations}

The institutional review board of each participating site reviewed and approved the study. Informed consent was obtained from parents/guardians or patients appropriately. Patients gave written assent where appropriate.

\section{Diagnosis of CD, UC, and IBDU}

Initial diagnosis was made by the center investigator, and the classification for disease type and location was done after reviewing the predetermined criteria. ${ }^{20}$ Disease behavior, location, and the presence of perianal disease were defined based on the Montreal classification system. ${ }^{21,22}$ Stricturing disease (B2) was defined as persistent luminal narrowing with prestenotic dilation observed by contrast small bowel imaging. Internal penetrating disease (B3) was defined as an intra-abdominal fistulizing disease resulting in an intra-abdominal or pelvic abscess or fistula to an adjacent organ, excluding the vagina or perianal region. B1 refers to uncomplicated inflammatory disease. Surgery is classified as those who underwent luminal surgery any time during the 3-year follow-up. Indications for surgery include strictures, bowel obstruction, or internal penetrating disease that did not respond to percutaneous drainage.

\section{Initial Management}

Patients were not managed by standardized protocols, but instead at the discretion of their local gastroenterologist. 
Early use of steroids, immunomodulators (IMs), or early antitumor necrosis factor (anti-TNF) exposure was defined by initiation of therapy within 90 days of diagnosis. Ever exposure was defined as exposure to IMs or anti-TNFs at any time during the 3 years of follow-up after diagnosis.

\section{Disease Monitoring}

Patients were followed longitudinally according to either individual center protocols or physician recommendation. Computerized tomography (CT), magnetic resonance enterography (MRE), small bowel followthrough (SBFT), and video capsule endoscopy were considered appropriate imaging for monitoring. No other type of imaging, including nuclear scan or ultrasound, was included.

\section{Statistics}

Frequencies and percentages were computed at the center level with site IDs de-identified and compared for center characteristics. Funnel plots were used to illustrate the intercenter variability of each outcome. The overall percentage is represented by a center line in each funnel plot. Upper and lower confidence limits at 95\% (2 SDs) and 99.9\% (3 SDs) are plotted against the center line and form the funnel, which provides a graphical display of permitted center-specific differences from the overall by random variation in patient characteristics and volume across the centers. The centers outside the funnel represent institutional practices that may be significantly different from the overall average. To analytically investigate the intercenter variations in each outcome, we used generalized linear mixed effects models. ${ }^{23}$ Patient-level factors (age at diagnosis, sex, race, and Physician Global Assessment [PGA] at diagnosis) and different follow-up times were controlled as the covariates and an offset, respectively, in all analyses. We assessed the difference in the average practices by center characteristic (geographic region), significance of intercenter variabilities overall, and difference in the intercenter variabilities within centers sharing the same center characteristics after accounting for difference and variations by patient-level factor. We used likelihood ratio tests at a significance level of 0.05 to address the latter 2 questions. The F-test was used to determine the significance of the difference in average practices by center characteristic (geographic region).

\section{RESULTS}

\section{Demographics of the Centers}

Out of the 28 centers that participated in the inception cohort study from the United States $(n=25)$ and Canada $(n=3)$, the number of subjects with $C D(n=1046)$ per center ranged from 5 to 112 (median, 31; mean, 37). In the United States, there were 12 centers from the Northeast, 5 from the Midwest, 7 from the South, and 4 from the West. The mean age of the 1046 patients (range) was 12.3 (2-18) years (Table 1). Subjects were mostly white $(74.1 \%$, ranging from $30 \%$ to $97.2 \%$ by center) and male $(61.1 \%)$. There were no differences with sex or age of onset among centers. According to the Montreal classification, small bowel disease (L1) was seen in $22 \%$, colonic disease (L2) was seen in $22 \%$, and ileocolonic disease (L3) was seen $54 \%$. The sex distribution, race, age of onset of CD, disease location, and presence of perianal disease at diagnosis were similar to previously published large cohorts in pediatrics. ${ }^{24,25}$

\section{Initial Diagnostic Approach}

Colonoscopy was performed on 1040 (99.4\%) of 1046 patients at baseline. Of these colonoscopies, the ileum was intubated $93.1 \%$ of the time (974), with no significant variation existing among centers after accounting for patientlevel factors (range, $57.1 \%-100 \% ; P=0.95$ ) (Table 2). One thousand twenty-three subjects $(97.8 \%)$ also had an upper endoscopy at baseline. However, only 778 subjects $(72.4 \%)$ (Supplementary Table 1) had small bowel imaging (MRE, CT, small bowel followthrough, or video capsule endoscopy), and the site-specific percentages of subjects' small bowel imaging ranged from $20 \%$ to $97.9 \%$, exhibiting a significant variation $(P<0.01)$ (Table 2).

\section{Initial Treatment Approach}

Medication data were analyzed based on 2 criteria: exposure within 90 days after diagnosis or ever exposed during the entire 3-year follow-up period. As we reported earlier, ${ }^{26}$ a 90-day cut-point for early introduction was chosen arbitrarily. Reported medications included 5 amino-salicylic acid (5-ASA), corticosteroids, immunomodulators (azathioprine [AZA]/6 mercaptopurine [6-MP], methotrexate), and anti-TNF drugs (infliximab or adalimumab).

\section{Corticosteroids}

A significant variation was seen in steroid exposure within 90 days, which varied from $28.6 \%$ to $96.9 \%$ among centers, with an overall usage of $68.2 \%(P<0.01)$. However, no significant variation was found in ever corticosteroid exposure during 3-year follow-up with the center-specific exposures ranging from $47.1 \%$ to $100 \%(P=0.13)$ (Table 2 and Fig. $1 \mathrm{~A}$ and $\mathrm{B}$ ). This indicates that variation existed during the initial treatment period with corticosteroids, but not during the later time.

\section{5-ASA}

Forty-five point two percent of patients were exposed to 5-ASA within 90 days (range, $0 \%-93.9 \%$ ); 47\% of patients were reported to be on 5-ASA during the entire follow-up (range, 0\%-93.9\%). Significant intercenter variation was noted $(P<0.01)$ (Supplementary Table 2), but variation among sites sharing the same geographic region was found to be similar $(P=$ not significant). The average percentage of 5-ASA use did 
TABLE 1. Demographic Characteristics of Children With Crohn's Disease by Site Characteristics

Moderate/Severe Disease Activity at

\begin{tabular}{|c|c|c|c|c|c|}
\hline \multicolumn{2}{|c|}{ Center-Level Characteristics } & \multirow{2}{*}{$\frac{\text { Age, Mean (SD), y }}{12.3(3.1)}$} & \multirow{2}{*}{$\frac{\text { Male, No. }(\%)}{640(61.1)}$} & \multirow{2}{*}{$\frac{\text { Nonwhite, No. }(\%)}{271(25.9)}$} & \multirow{2}{*}{$\begin{array}{r}\text { Diagnosis According to } P \\
682(65.2)\end{array}$} \\
\hline Overall & - & & & & \\
\hline \multirow[t]{28}{*}{ Site } & 1 & $13.0(3.6)$ & $7(50.0)$ & $2(14.3)$ & $11(78.6)$ \\
\hline & 2 & $12.3(3.1)$ & $19(51.3)$ & 7 (18.9) & $16(43.2)$ \\
\hline & 3 & $12.9(2.8)$ & $20(66.6)$ & $21(70.0)$ & $27(90.0)$ \\
\hline & 4 & $11.7(2.9)$ & $36(61.0)$ & $13(22.0)$ & 37 (62.7) \\
\hline & 5 & $12.8(3.1)$ & $76(67.8)$ & $40(35.7)$ & $82(73.2)$ \\
\hline & 6 & $12.1(3.1)$ & $13(37.1)$ & $9(25.7)$ & $30(85.7)$ \\
\hline & 7 & $12.1(3.0)$ & $62(60.7)$ & $16(15.7)$ & 69 (67.6) \\
\hline & 8 & $11.6(3.2)$ & $9(52.9)$ & $7(41.1)$ & $15(88.2)$ \\
\hline & 9 & $12.1(2.5)$ & $6(75.0)$ & $3(37.5)$ & $5(62.5)$ \\
\hline & 10 & $12.1(3.0)$ & $29(65.9)$ & $5(11.3)$ & $26(59.1)$ \\
\hline & 11 & $12.4(3.0)$ & $36(65.4)$ & $30(54.5)$ & $36(65.4)$ \\
\hline & 12 & $12.0(3.5)$ & $6(85.7)$ & $1(14.2)$ & $4(57.1)$ \\
\hline & 13 & $12.6(3.2)$ & $58(64.4)$ & $28(31.1)$ & $43(47.8)$ \\
\hline & 14 & $12.2(3.1)$ & $17(70.8)$ & $1(4.1)$ & $19(79.2)$ \\
\hline & 15 & $11.6(4.2)$ & $19(57.6)$ & $11(33.3)$ & $16(48.5)$ \\
\hline & 16 & $14.3(2.2)$ & $16(69.6)$ & $3(13.0)$ & $13(56.5)$ \\
\hline & 17 & $11.5(3.2)$ & $18(51.4)$ & $1(2.8)$ & $34(97.1)$ \\
\hline & 18 & $12.3(3.3)$ & $54(62.8)$ & $20(23.2)$ & 73 (84.9) \\
\hline & 19 & $12.7(3.0)$ & $10(55.6)$ & $6(33.3)$ & $5(27.8)$ \\
\hline & 20 & $12.8(2.2)$ & $2(40.0)$ & $1(20.0)$ & $3(100.0)$ \\
\hline & 21 & $11.8(3.0)$ & $29(60.4)$ & 7 (14.6) & $13(27.1)$ \\
\hline & 22 & $11.7(3.6)$ & $19(63.3)$ & $13(43.3)$ & $19(63.3)$ \\
\hline & 23 & $12.8(3.2)$ & $21(65.6)$ & $10(31.2)$ & $29(90.6)$ \\
\hline & 24 & $11.3(3.4)$ & $10(55.6)$ & 7 (38.9) & 7 (38.9) \\
\hline & 25 & $13.1(1.3)$ & $3(42.8)$ & $1(14.3)$ & $4(57.1)$ \\
\hline & 26 & $11.6(3.2)$ & $13(54.1)$ & $4(16.7)$ & $17(70.8)$ \\
\hline & 27 & $11.9(2.4)$ & $22(62.8)$ & $3(8.6)$ & $23(65.7)$ \\
\hline & 28 & $11.7(3.3)$ & $10(55.6)$ & $1(5.6)$ & $6(33.3)$ \\
\hline \multirow{4}{*}{$\begin{array}{l}\text { Geographic } \\
\text { region }\end{array}$} & Midwest & $11.9(3.0)$ & $146(60.8)$ & $41(17.1)$ & $140(58.3)$ \\
\hline & Northeast & $12.4(3.2)$ & $342(63.0)$ & 135 (24.9) & 351 (64.6) \\
\hline & South & $12.7(3.0)$ & $106(63.1)$ & $75(44.6)$ & 107 (63.7) \\
\hline & West & $11.8(3.0)$ & $46(48.4)$ & $20(21.0)$ & $84(88.4)$ \\
\hline
\end{tabular}

not differ among different geographic regions (Supplementary Table 3).

\section{Immunomodulators}

Unlike corticosteroids, there was a significant intercenter variation in both 90-day and 3-year exposure to IM. (Table 2 and Fig. 1C and D). In our study, 50.1\% of the patients received IM within the first 90 days of diagnosis. There was a wide range of variation among centers (range, $0 \%-91.4 \% ; P<0.01$ ) (Table 2 and Fig. 1C). This variation was also seen with ever exposure to IM during the 3-year follow-up (range, $24.4 \%-100 \%$, with an overall usage of $73.7 \% ; P<0.01$ ) (Table 2 and Fig. 1D). Furthermore, when centers were grouped by geographic region, intercenter variation was greater within certain geographic regions than others ( $P=0.01$ for the exposure within 90 days after diagnosis; $P=0.02$ for the exposure any time during follow-up) (Table 2). Centers in the Midwest displayed the highest geographic regional average usage ( $70.8 \%$ early and $88.3 \%$ ever) with the least variation in IM treatment practice among themselves. Northeast centers have the lowest geographic regional average use of early (39.2\%) and cumulative (66.5\%) IM treatment with the biggest variation among themselves (Fig. 1C and D; Supplementary Table 4).

Overall use of 6MP/AZA (range) was $53.3 \%(9.3 \%-$ $89.6 \%)$, and methotrexate use was $38.8 \% \quad(0 \%-87.5 \%)$ 
TABLE 2. Likelihood Ratio Test of Overall Intercenter Variability in Clinical Practice in Pediatric Crohn's Disease and Variations Between Centers Sharing Different Characteristics

\begin{tabular}{|c|c|c|}
\hline & $\begin{array}{l}\text { Significance of Intercenter } \\
\text { Variability, } P^{\mathrm{a}}\end{array}$ & $\begin{array}{l}\text { Significance of Difference in the } \\
\text { Intercenter Variabilities by } \\
\text { Geographic Region, } P^{\mathrm{b}}\end{array}$ \\
\hline Baseline endoscopy & $>0.99$ & $>0.99$ \\
\hline Baseline small bowel imaging & $<0.01$ & $<0.01$ \\
\hline Baseline upper GI endoscopy & $>0.99$ & $>0.99$ \\
\hline Baseline colonoscopy up to terminal ileum & $<0.01$ & 0.46 \\
\hline Follow-up endoscopy & $<0.01$ & 0.51 \\
\hline Follow-up small bowel imaging & $<0.01$ & 0.28 \\
\hline Follow-up upper GI endoscopy & $<0.01$ & 0.13 \\
\hline Follow-up with either endoscopy or small bowel imaging & 0.26 & 0.75 \\
\hline Steroid exposure within $90 \mathrm{~d}$ & $<0.01$ & 0.03 \\
\hline Steroid exposure ever used in $3 \mathrm{y}$ & 0.20 & 0.39 \\
\hline 5-ASA exposure within $90 \mathrm{~d}$ & $<0.01$ & 0.25 \\
\hline 5-ASA exposure ever used in $3 \mathrm{y}$ & $<0.01$ & 0.22 \\
\hline Immunomodulator within $90 \mathrm{~d}$ & $<0.01$ & $<0.01$ \\
\hline Immunomodulator ever used in $3 \mathrm{y}$ & $<0.01$ & 0.01 \\
\hline Anti-TNF within $90 \mathrm{~d}$ & $<0.01$ & 0.65 \\
\hline Anti-TNF within $183 \mathrm{~d}$ & $<0.01$ & 0.59 \\
\hline Anti-TNF within $365 \mathrm{~d}$ & $<0.01$ & 0.60 \\
\hline Anti-TNF ever used in $3 \mathrm{y}$ & $>0.99$ & 0.95 \\
\hline Neither immunomodulator nor anti-TNF within $90 \mathrm{~d}$ & $<0.01$ & 0.12 \\
\hline Neither immunomodulator nor anti-TNF ever used in $3 \mathrm{y}$ & $<0.01$ & 0.44 \\
\hline
\end{tabular}

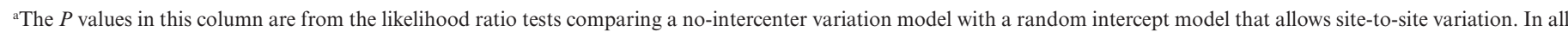
models, patient-level factors (age at diagnosis, Physician Global Assessment at diagnosis, sex, and race) are controlled for.

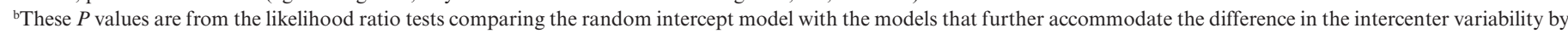
the corresponding center characteristics. This $P$ value shows the significance of the difference in variations between centers sharing different characteristics.

(Supplementary Table 5). The use of 6MP/AZA differed between geographic regions $(P=0.001)$, where the Midwest region had the higher percentage $(81.7 \%)$ of thiopurine use compared with the other 3 regions (Supplementary Table 6).

\section{Anti-TNF}

A significant intercenter variation in use of anti-TNF during the first 90 days was seen (range, 2.1\%-65.7\%; $P<0.01$ ), but the variability did not differ significantly by center group characteristics or geographic region $(P=0.65)$ (Table 2). However, when ever exposed to anti-TNF during the 3 years of follow-up is considered, centers depicted more similarity to each other, with an overall percentage use of $65.9 \%(P>0.99)$ (Table 2 and Fig. 1E and F).

Despite similar variation within each geographic region, the average regional practice of early anti-TNF use was significantly different $(P=0.025,0.023$, and 0.034 for within 90 days, within 6 months, and within 1 year, respectively) (Table 3). Centers in the South $(36.9 \%)$ and West $(42.1 \%)$ regions showed earlier use of anti-TNF compared with centers in the Midwest
(14.6\%) and Northeast (18.4\%) regions. A similar pattern was observed during up to 1 year of anti-TNF use, but these differences disappeared by 3 years $(P=0.54)$ (Table 3$)$ as the centers in the Northeast and Midwest started to use more anti-TNF during the second and third years of follow-up (Supplementary Table 7). Infliximab was the most used anti-TNF (range, $21.6 \%-85.7 \%$ ), whereas adalimumab use was reported to be in the range of $2.9 \%$ to $60 \%$.

Still, there was a delay in initiating either IM or antiTNF early. When within 90 days of drug exposure was considered, $32.5 \%$ of the subjects did not receive any IM or biologics, whereas $45 \%$ received IM only, $17.4 \%$ received anti-TNF only, and $5.3 \%$ of patients received a combination with both IM and anti-TNF (Supplementary Table 8).

\section{Combination therapy}

There was a significant intercenter variation in the early selection of IM and anti-TNF $(P<0.01)$. The use of early IM alone was seen in $45 \%$ (range, $0 \%-84.4 \%$ ), whereas antiTNF alone was $17.4 \%$ (range, $0 \%-57.1 \%$ ). When considering 

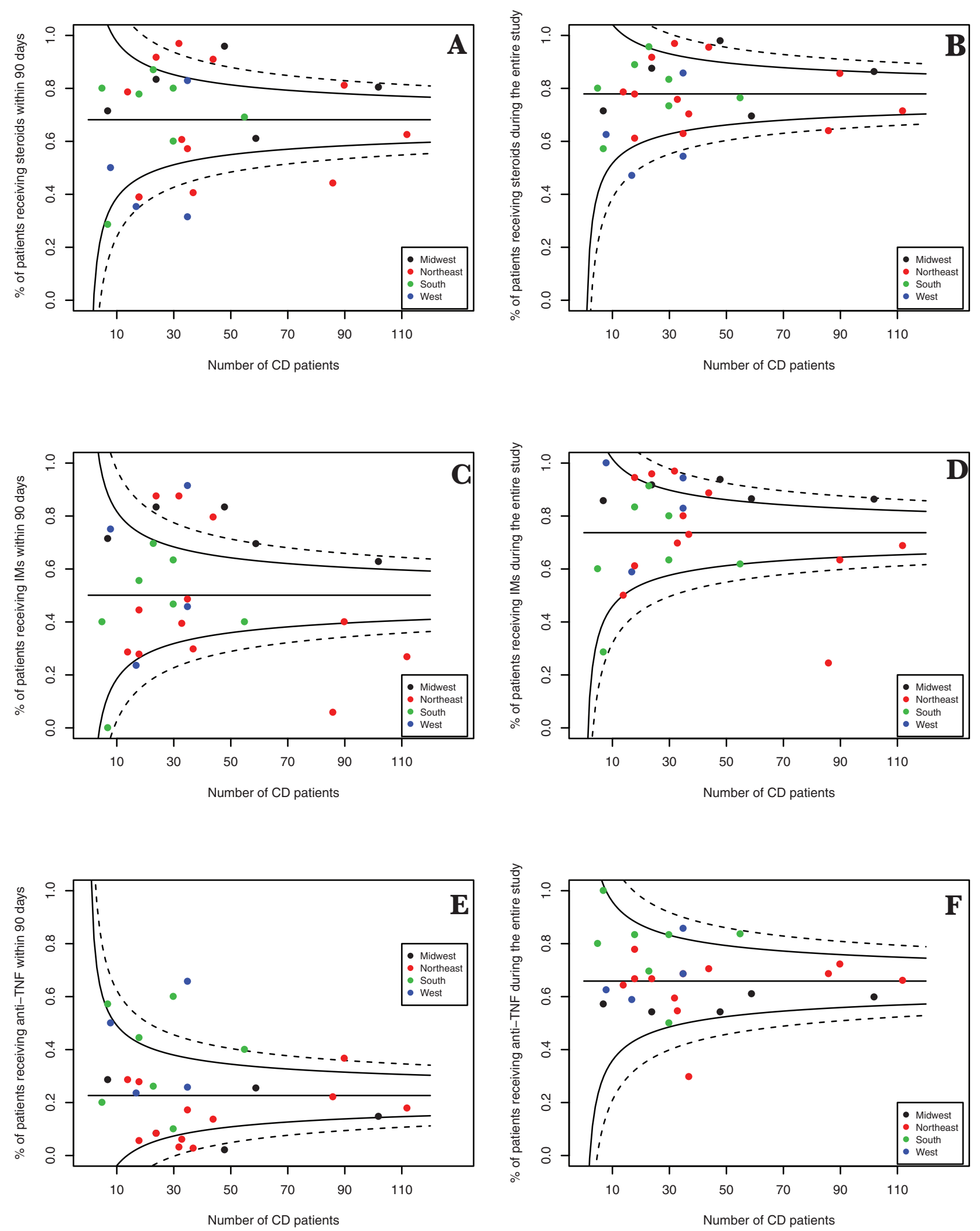

FIGURE 1. A, Percentage of patients who received steroids within 90 days of diagnosis. B, Percentage of patients who received steroids during the entire period of study. C, Percentage of patients who received immunomodulators within 90 days of diagnosis. D, Percentage of patients who received immunomodulators during the entire period of the study. E, Percentage of patients who received anti-TNF within 90 days of diagnosis. F, Percentage of patients who received anti-TNF during the entire period of the study. 
the entire 3-year period of treatment, $50.5 \%$ (range, 20.9\%$77.8 \%$ ) of patients had combination therapy with both IM and anti-TNF, whereas $15.4 \%$ (range, $0 \%-71.4 \%$ ) of patients had only anti-TNF and $23.2 \%$ (range, $0 \%-42.9 \%$ ) had IM only

TABLE 3. Difference in Average Practice by CenterLevel Characteristics

Significance of Difference in Average Practice by

Geographic Region, $P^{a}$

$\begin{array}{ll}\text { Baseline colonoscopy } & 0.96 \\ \text { Baseline small bowel imaging } & 0.17 \\ \text { Baseline upper GI endoscopy } & 0.98 \\ \text { Baseline colonoscopy up to terminal } & 0.90 \\ \quad \text { ileum } & \\ \text { Follow-up colonoscopy } & 0.60 \\ \text { Follow-up small bowel imaging } & 0.76 \\ \text { Follow-up upper GI endoscopy } & 0.77 \\ \text { Follow-up with either colonoscopy } & 0.60 \\ \quad \text { or small bowel imaging } & \\ \text { Steroid exposure within } 90 \mathrm{~d} & 0.36 \\ \text { Steroid exposure ever used in } 3 \text { y } & 0.58 \\ \text { Immunomodulator within } 90 \mathrm{~d} & 0.11 \\ \text { Immunomodulator ever used in } 3 \mathrm{y} & 0.36 \\ \text { Anti-TNF within } 90 \mathrm{~d} & 0.03 \\ \text { Anti-TNF within } 183 \mathrm{~d} & 0.02 \\ \text { Anti-TNF within } 365 \mathrm{~d} & 0.03 \\ \text { Anti-TNF ever used in } 3 \mathrm{y} & 0.54 \\ \text { Neither immunomodulator nor } & 0.03 \\ \quad \text { anti-TNF within } 90 \mathrm{~d} & \\ \text { Neither immunomodulator nor } & 0.02 \\ \text { anti-TNF ever used in } 3 \text { y } & \end{array}$

aThe $P$ values are from the GLMM F-test, which determines the significance of difference in the average practices by the corresponding center characteristic.
(Supplementary Table 8). The average percentage of those using neither IM nor anti-TNF was not equal among geographic regions $(P=0.03$ and 0.02 for the early and cumulative, respectively). The Northeast has the highest percentage of using neither within 90 days $(46.2 \%)$ or during the entire follow-up (16.4\%) (Table 4).

\section{Disease Monitoring With Follow-up Imaging and Endoscopies}

As this is an observational cohort without a specified follow-up protocol in place, follow-up visits or disease monitoring imaging/endoscopies were performed solely at the discretion of the treating clinician. During the 3-year follow-up period, $50 \%$ (range, $12.5 \%-82.6 \%$ ) of patients underwent repeat upper gastrointestinal (GI) endoscopic evaluation and 64.2\% (range, 38.9\%-100\%) had small bowel imaging (abdominal CT, abdominal/pelvic MRE, or video capsule endoscopy). Taken together, only $79.4 \%$ of patients had either repeat colonoscopy or imaging during their 3-year follow-up period, leaving 20.6\% of patients without any repeat evaluation (Supplementary Table 1). There was no significant intercenter variation among centers $(P=0.29)$ or geographic regions $(P=0.90)$ with regard to repeat endoscopic or imaging evaluation (Table 2$)$.

\section{Disease Outcome Variation During 3-Year Follow-up}

Overall there were 145 stricturing $(13.9 \%$, ranging from $0 \%$ to $28.6 \%$ per center) and 60 penetrating $(5.7 \%$, ranging from $0 \%$ to $12.5 \%$ per center) complications, with $121(11.6 \%$, ranging from $0 \%$ to $42.9 \%$ per center) requiring resective surgeries (Supplementary Table 9). Neither complicated disease nor surgery rate varied among the participating centers. The event rate of only $11.6 \%$ did not allow us to assess if variation in care influenced the complicated outcome. Complications are evolving, and dynamic events in $\mathrm{CD}$ and longer follow-up with more

TABLE 4. Intercenter Variation in IM and/or Anti-TNF Use by Geographic Region

\begin{tabular}{|c|c|c|c|c|c|c|c|c|c|}
\hline \multirow[b]{3}{*}{ Category } & \multirow[b]{3}{*}{ No. } & \multicolumn{4}{|c|}{ Within $90 \mathrm{~d}$ of Diagnosis, No. $(\%)$} & \multicolumn{4}{|c|}{ Ever Used in 3 y, No. $(\%)$} \\
\hline & & & & Anti-TNF & & & & Anti-TNF & \\
\hline & & Neither & IM Only & Only & Both & Neither & IM Only & Only & Both \\
\hline Overall & 1046 & $340(32.5)$ & $469(44.8)$ & $182(17.4)$ & $55(5.3)$ & $114(10.9)$ & $243(23.2)$ & $161(15.4)$ & $528(50.5)$ \\
\hline $\begin{array}{l}\text { Geographic } \\
\text { region, } P^{\text {a }}\end{array}$ & & 0.03 & & & & 0.02 & & & \\
\hline Midwest & 240 & $42(17.5)$ & $163(67.9)$ & $28(11.7)$ & $7(2.9)$ & $10(4.2)$ & $90(37.5)$ & $18(7.5)$ & $122(50.8)$ \\
\hline Northeast & 543 & $251(46.2)$ & $192(35.4)$ & $79(14.5)$ & $21(3.9)$ & $89(16.4)$ & $102(18.8)$ & $93(17.1)$ & $259(47.7)$ \\
\hline South & 168 & $33(19.6)$ & $73(43.5)$ & $52(31.0)$ & $10(6)$ & $9(5.4)$ & $31(18.5)$ & $41(24.4)$ & $87(51.8)$ \\
\hline West & 95 & $14(14.7)$ & $41(43.2)$ & $23(24.2)$ & 17 (17.9) & $6(6.3)$ & $20(21.1)$ & $9(9.5)$ & $60(63.2)$ \\
\hline
\end{tabular}

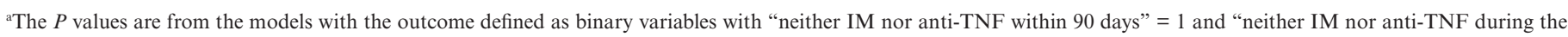
entire follow-up" $=1$. 
events of complication are necessary to evaluate if variation in care influences the outcome or natural history of $\mathrm{CD}$.

\section{DISCUSSION}

It has been established that variation in care exists in the diagnosis and management of IBD in pediatrics. ${ }^{811}$ Over the last 2 decades, practice guidelines have been published in both pediatric and adult IBD. ${ }^{27-31}$ There have been several initiatives to decrease variation in IBD care in North America, including quality improvement projects ${ }^{9,32-35}$ and multicenter collaborative studies. ${ }^{16,36}$ Previous publications addressing variation in care were limited by a small number of subjects, and they did not include the variation among geographic regions or antiTNF in the treatment paradigm. ${ }^{8}$ Furthermore, there have been only a few large studies addressing the variation of care in pediatric IBD since 2007.9, 10,35 Our 28-center, 1046-subject inception cohort study with prospective, standardized 6-month to 3-year follow-up and 3-year disease course data offers an unprecedented opportunity for reevaluation of care variance. Although there has been a decrease in variation of certain aspects of care including colonoscopy/ileoscopy in the diagnostic approach to $\mathrm{IBD}$, we continue to see a large variation in care with regard to treatment and disease monitoring.

A study from the United Kingdom in 2003 by Sawczenko et al. concluded that patients receive different care according to their geographic region and choice of specialist category (pediatric or adult gastroenterologist vs adult services). ${ }^{7}$ This study showed that children had less chance to undergo colonoscopy and more chance to undergo sigmoidoscopy if they were receiving care from adult services. No further studies have been published in the United Kingdom on this subject since then, and the practices have likely changed in the United Kingdom. Our study clearly shows that all the centers in North America now have universally adopted full colonoscopy rather than sigmoidoscopy in the diagnosis of pediatric IBD. Although there was a little variation with the initial diagnostic approach, follow-up endoscopies either for disease reevaluation or surveillance varied significantly. This may have been due to patient preferences, physician choices, availability of institutional resources, or cost-related issues. ${ }^{7,8}$ Emerging data from recent IBD literature suggest that tight control of inflammation using therapeutic drug monitoring and endoscopic evaluation can result in better mucosal healing outcomes. ${ }^{37-40}$ Many pediatric gastroenterology centers that participated in this study now consider mucosal healing to be one of the main goals of therapy, rather than symptom improvement. There still are no reliable surrogate markers for mucosal healing, and hence repeat endoscopic evaluation is considered one of the best ways to assess mucosal healing, particularly in colonic disease. ${ }^{41}$ However, possible barriers to such an approach include cost, insurance approval, and patient acceptance. Future implementation of various practice strategies may help reduce the variation in care. ${ }^{42}$
Even though corticosteroids and IM have been the mainstay of treatment in IBD care among children, we noted an increasing trend in the early use of anti-TNFs, particularly within 90 days of diagnosis. ${ }^{8,26}$ Remarkably, almost half of all patients received 5-ASA despite the lack of published evidence of efficacy in adults or children with Crohn's disease; we have excluded it in the final analysis. ${ }^{43-45}$ Our study demonstrates significant intercenter variation in adopting early anti-TNF use. We speculate that payer/insurance preferences, ${ }^{15}$ physician expertise, and patients' preferences for oral vs intravenous or subcutaneous drugs are possible reasons for the observed variability in treatment. Interestingly, our study shows that even though centers differed significantly in the early use of antiTNFs, they all had similar levels of usage after 1 year. The centers that used early anti-TNFs had less use of IMs and corticosteroids.

Almost a decade ago, Kappelman et al. ${ }^{8}$ evaluated variation of care in IBD management among 10 pediatric gastrointestinal centers across North America. Among other findings, he and his colleagues found statistically significant variation in the use of IMs among centers. Since then, several events have taken place in the pediatric IBD community, including the creation and implementation of the global ICN initiative to reduce variation in care among centers. ${ }^{34,46}$ More than 100 pediatric IBD centers worldwide (97 centers in the United States, 9 in Belgium, 1 in Qatar, and 2 in the United Kingdom), 950 pediatric gastroenterologists, and close to 30,000 children with IBD participated in the ICN initiative, which measures care for patients with both CD and UC. This has resulted in $93 \%$ achieving satisfactory growth, $81 \%$ achieving remission $(54 \%$ have sustained remission), and $90 \%$ achieving satisfactory nutrition (https://www.improvecarenow.org/purpose-success). Out of 28 sites from the RISK study, 16 participated in ICN and 12 did not. Unfortunately, many sites joined ICN during the course of the RISK study, and there was not enough follow-up time to make any meaningful analysis or conclusions regarding the impact of ICN in reducing the intercenter variation in care. Future studies will be of great interest to see if the ICN initiatives have impacted variation of care in the diagnosis, treatment, and disease monitoring of CD.

Although our study is the largest to date, involving $>1000$ subjects from a treatment-naïve inception cohort from 28 sites in North America, there are several limitations to our study. The clinical practice of pediatric IBD is constantly changing, and the current approach in the year 2018 may not be the same compared with our study, which took place between 2008 and 2015. Recent years have seen an increasing use of methotrexate compared with 6-MP (thiopurines) due to concern for lymphoma. ${ }^{47,48}$ Additionally, new biologic therapies such as anti-adhesions and anti-IL12/23 are increasingly being used in pediatric gastroenterology, though they have not yet been approved in pediatrics, which could lead to further variation 
in care. ${ }^{49-51}$ Our study did not include any methods to check for medication adherence.

In conclusion, a wide variation in IBD care continues to exist among North American centers regarding management and disease monitoring. Intercenter variation in the early use of anti-TNFs did not persist beyond 1 year, suggesting that regardless of corticosteroids and IM treatment, anti-TNFs are eventually used at similar rates among patients at all centers. Randomized control trials among pediatric IBD patients are needed to answer some of these questions. When randomized control trials are not possible or ethically justifiable, then standardized practice guidelines should be developed across many centers using the factors we have identified as the implementation of these evidence-based guidelines may reduce variation in care.

\section{SUPPLEMENTARY DATA}

Supplementary data are available at Inflammatory Bowel Diseases online.

\section{ACKNOWLEDGMENTS}

We thank Hari Somineni and Suresh Venkateswaran for helping with data accrual, graphics, and critical reading of this manuscript.

\section{REFERENCES}

1. Kappelman MD, Rifas-Shiman SL, Kleinman K, et al. The prevalence and geographic distribution of Crohn's disease and ulcerative colitis in the United States. Clin Gastroenterol Hepatol. 2007;5:1424-1429.

2. Kappelman MD, Moore KR, Allen JK, et al. Recent trends in the prevalence of Crohn's disease and ulcerative colitis in a commercially insured US population. Dig Dis Sci. 2013;58:519-525.

3. Kornbluth A. Infliximab approved for use in Crohn's disease: a report on the FDA GI Advisory Committee conference. Inflamm Bowel Dis. 1998;4:328-329.

4. Tremaine WJ. Biologics for inflammatory bowel disease: drug approval and monitoring in the United States. Gastroenterol Clin North Am. 2006;35:735-41.

5. Van Assche G, Vermeire S, Rutgeerts P. Adalimumab in Crohn's disease. Biologics. 2007; 1:355-65.

6. Lahiff C, Kane S, Moss AC. Drug development in inflammatory bowel disease: the role of the FDA. Inflamm Bowel Dis. 2011;17:2585-2593.

7. Sawczenko A, Lynn R, Sandhu BK. Variations in initial assessment and management of inflammatory bowel disease across Great Britain and Ireland. Arch Dis Child. 2003;88:990-994.

8. Kappelman MD, Bousvaros A, Hyams J, et al. Intercenter variation in initial management of children with Crohn's disease. Inflamm Bowel Dis. 2007; 13:890-895.

9. Colletti RB, Baldassano RN, Milov DE, et al; Pediatric IBD Network for Research and Improvement. Variation in care in pediatric Crohn disease. J Pediatr Gastroenterol Nutr. 2009;49:297-303.

10. Adler J, Sandberg KC, Shpeen $\mathrm{BH}$, et al. Variation in infliximab administration practices in the treatment of pediatric inflammatory bowel disease. $J$ Pediatr Gastroenterol Nutr. 2013;57:35-38

11. Dotson JL, Nwomeh B, Andridge R, et al. Variation in management of intra-abdominal abscesses in children with Crohn's disease. Inflamm Bowel Dis. 2013;19:818-825.

12. Wennberg JE. Unwarranted variations in healthcare delivery: implications for academic medical centres. BMJ. 2002;325:961-964.

13. Johnson C, Butler SM, Konstan MW, et al. Factors influencing outcomes in cystic fibrosis: a center-based analysis. Chest. 2003;123:20-27.

14. Esrailian E, Spiegel BM, Targownik LE, et al. Differences in the management of Crohn's disease among experts and community providers, based on a national survey of sample case vignettes. Aliment Pharmacol Ther. 2007;26:1005-1018.

15. Yadav A, Foromera J, Feuerstein I, et al. Variations in health insurance policies regarding biologic therapy use in inflammatory bowel disease. Inflamm Bowel Dis. 2017;23:853-857.
16. Crandall WV, Margolis PA, Kappelman MD, et al; ImproveCareNow Collaborative. Improved outcomes in a quality improvement collaborative for pediatric inflammatory bowel disease. Pediatrics. 2012;129:e1030-e1041.

17. Savarino JR, Kaplan JL, Winter HS, Moran CJ, Israel EJ. Improving clinical remission rates in pediatric inflammatory bowel disease with previsit planning. BMJ Qual Improv Rep. 2016;5:1-5.

18. Siegel CA, Allen JI, Melmed GY. Translating improved quality of care into an improved quality of life for patients with inflammatory bowel disease. Clin Gastroenterol Hepatol. 2013;11:908-912.

19. US Census Bureau. Geography atlas regions. 2015. https://www.census.gov/geo/ reference/webatlas/regions.html. Accessed September 4, 2018

20. Walters TD, Kim MO, Denson LA, et al; PRO-KIIDS Research Group Increased effectiveness of early therapy with anti-tumor necrosis factor- $\alpha$ vs an immunomodulator in children with Crohn's disease. Gastroenterology. 2014;146:383-391.

21. Satsangi J, Silverberg MS, Vermeire S, et al. The Montreal classification of inflammatory bowel disease: controversies, consensus, and implications. Gut. 2006;55:749-753.

22. Silverberg MS, Satsangi J, Ahmad T, et al. Toward an integrated clinical, molecular and serological classification of inflammatory bowel disease: report of a Working Party of the 2005 Montreal World Congress of Gastroenterology. Can J Gastroenterol. 2005;19(Suppl A):5A-36A.

23. McCulloch CE, Searle SR, Neuhaus JM. Generalized Linear and Mixed Models. 2nd ed. Hoboken, NJ: John Wiley \& Sons; 2011.

24. Hyams J, Markowitz J, Lerer T, et al; Pediatric Inflammatory Bowel Disease Collaborative Research Group. The natural history of corticosteroid therapy for ulcerative colitis in children. Clin Gastroenterol Hepatol. 2006;4:1118-1123.

25. Keljo DJ, Markowitz J, Langton C, et al. Course and treatment of perianal disease in children newly diagnosed with Crohn's disease. Inflamm Bowel Dis. 2009; 15:383-387.

26. Kugathasan S, Denson LA, Walters TD, et al. Prediction of complicated disease course for children newly diagnosed with Crohn's disease: a multicentre inception cohort study. Lancet. 2017;389:1710-1718.

27. Terdiman JP, Gruss CB, Heidelbaugh JJ, et al; AGA Institute Clinical Practice and Quality Management Committee. American Gastroenterological Association Institute guideline on the use of thiopurines, methotrexate, and anti-TNF- $\alpha$ biologic drugs for the induction and maintenance of remission in inflammatory Crohn's disease. Gastroenterology. 2013;145:1459-1463

28. Nguyen GC, Loftus EV Jr, Hirano I, et al; AGA Institute Clinical Guidelines Committee. American Gastroenterological Association Institute guideline on the management of Crohn's disease after surgical resection. Gastroenterology. 2017; $152: 271-275$

29. American Gastroenterological Association. IBD \& bowel disorders guidelines 2018. https://www.gastro.org/guidelines/ibd-and-bowel-disorders. Accessed September 29, 2018

30. Ruemmele FM, Veres G, Kolho KL, et al; European Crohn's and Colitis Organisation; European Society of Pediatric Gastroenterology, Hepatology and Nutrition. Consensus guidelines of ECCO/ESPGHAN on the medical management of pediatric Crohn's disease. J Crohns Colitis. 2014;8:1179-1207.

31. Day AS, Gulati AS, Patel N, et al. The role of combination therapy in pediatric inflammatory bowel disease: a clinical report from the North American Society for Pediatric Gastroenterology, Hepatology and Nutrition. J Pediatr Gastroentero Nutr. 2018;66:361-368.

32. Ahmed S, Siegel CA, Melmed GY. Implementing quality measures for inflammatory bowel disease. Curr Gastroenterol Rep 2015;17:14.

33. Melmed GY, Siegel CA. Quality improvement in inflammatory bowel disease Gastroenterol Hepatol ( $N$ Y). 2013:9:286-292.

34. Shah R, Hou JK. Approaches to improve quality of care in inflammatory bowel diseases. World J Gastroenterol. 2014;20:9281-9285.

35. Crandall W, Kappelman MD, Colletti RB, et al. ImproveCareNow: the development of a pediatric inflammatory bowel disease improvement network. Inflamm Bowel Dis. 2011;17:450-457.

36. Arvanitis M, DeWalt DA, Martin CF, et al. Patient-reported outcomes measurement information system in children with Crohn's disease. $J$ Pediatr. 2016;174:153-159.e2

37. Ananthakrishnan AN, Cagan A, Cai T, et al. Colonoscopy is associated with a reduced risk for colon cancer and mortality in patients with inflammatory bowel diseases. Clin Gastroenterol Hepatol. 2015;13:322-329 e1.

38. Passos MAT, Chaves FC, Chaves-Junior N. The importance of colonoscopy in inflammatory bowel diseases. Arq Bras Cir Dig. 2018;31:1-4.

39. Vande Casteele N, Herfarth H, Katz J, et al. American Gastroenterologica Association Institute technical review on the role of therapeutic drug monitoring in the management of inflammatory bowel diseases. Gastroenterology. 2017:153:835-857.e6.

40. Wright EK, Kamm MA, De Cruz P, et al. Anti-TNF therapeutic drug monitoring in postoperative Crohn's disease. J Crohns Colitis. 2018;12:653-661.

41. Mao R, Qiu Y, Chen BL, et al. Factors associated with the achievement of mucosal healing in Crohn's disease: the benefit of endoscopic monitoring in treating to target. Therap Adv Gastroenterol. 2017;10:453-463. 
42. Neuhauser D, Provost L, Bergman B. The meaning of variation to healthcare managers, clinical and health-services researchers, and individual patients. $B M J$ Qual Saf. 2011;20(Suppl 1):i36-i40.

43. Ford AC, Kane SV, Khan KJ, et al. Efficacy of 5-aminosalicylates in Crohn's disease: systematic review and meta-analysis. Am J Gastroenterol. 2011;106:617-629.

44. Ma C, Ascoytia C, McCarrier KP, et al. Physicians' perspectives on cost, safety, and perceived efficacy determine aminosalicylate use in Crohn's disease. Dig Dis Sci. 2018;63:2555-2563.

45. Zeisler B, Lerer T, Hyams J. Utilization and clinical outcome following 5-aminosalicylate therapy for crohn's disease in children. J Gastroenterol Hepatology Res. 2018;3:016

46. Dykes D, Williams E, Margolis $\mathrm{P}$, et al. Improving pediatric inflammatory bowel disease (IBD) follow-up. BMJ Qual Improv Rep. 2016;5:1-8.
47. Lopez A, Mounier M, Bouvier AM, et al; CESAME Study Group. Increased risk of acute myeloid leukemias and myelodysplastic syndromes in patients who received thiopurine treatment for inflammatory bowel disease. Clin Gastroenterol Hepatol. 2014;12:1324-1329.

48. Lemaitre M, Kirchgesner J, Rudnichi A, et al. Association between use of thiopurines or tumor necrosis factor antagonists alone or in combination and risk of lymphoma in patients with inflammatory bowel disease. JAMA. 2017;318:1679-1686.

49. Bishop C, Simon H, Suskind D, et al. Ustekinumab in pediatric Crohn disease patients. J Pediatr Gastroenterol Nutr. 2016;63:348-351.

50. Conrad MA, Stein RE, Maxwell EC, et al. Vedolizumab therapy in severe pediatric inflammatory bowel disease. Inflamm Bowel Dis. 2016;22:2425-2431.

51. Singh N, Rabizadeh S, Jossen J, et al. Multi-center experience of vedolizumab effectiveness in pediatric inflammatory bowel disease. Inflamm Bowel Dis. 2016;22:2121-2126. 